\title{
Self-medication, used medications, and symptoms among nurses providing care to pregnant women with coronavirus disease 2019
}

\author{
Hamid Owaysee Osquee $^{1}$, Abbasali Dorosti ${ }^{\circledR}{ }^{\mathbb{D}}$, Shervin Tabrizian-Namin ${ }^{3 *}$ \\ ${ }^{1}$ Assistant Professor of Infectious Disease, Faculty of Medicine, Tabriz University of Medical Sciences, Tabriz, Iran \\ ${ }^{2}$ Associated Professor of Anesthesiology, Faculty of Medicine, Tabriz University of Medical Sciences, Tabriz, Iran \\ ${ }^{3}$ Obstetrics \& Gynecology, Faculty of Medicine, Ardabil University of Medical Sciences, Ardabil, Iran
}

\begin{abstract}
Background and aims: The prevalence of coronavirus disease 2019 (COVID-19) among nurses who provide care to pregnant women may lead to self-medication (SM) among them as well as recommendation of SM to pregnant women. There is limited information about SM among nurses during the COVID-19 pandemic. This study sought to evaluate SM, used medications, and symptoms among nurses providing care to pregnant women with COVID-19.

Methods: This cross-sectional descriptive-analytical study was conducted in a four-month period from March 21 to July 22, 2020. Participants were 125 nurses who were providing care to pregnant women in Imam Reza teaching hospital, Tabriz, Iran. A sociodemographic characteristics questionnaire and a questionnaire on SM contributing factors were used to collect the data. The SPSS software (v. 21.0) was used to analyze the data at a significance level of less than 0.05 through the chi-square test.

Results: The prevalence of SM among nurses was $40.83 \%$. SM had significant relationship with the use of antibiotics $(P=0.012)$, herbal medicines $(P=0.028)$, multivitamins $(P=0.035)$, and analgesics $(P=0.044)$. Moreover, SM had significant relationship with nausea $(P=0.036)$, fever $(P=0.019)$, headache $(P=0.044)$, and diarrhea $(P=0.021)$.

Conclusion: SM is highly prevalent among nurses who provide care to pregnant women with COVID-19. Keywords: Coronavirus disease 2019, Self-medication, Antibiotic, Pregnancy, Nurse
\end{abstract}

*Corresponding Author: Shervin Tabrizian-Namin Email: shervin_tabrizian@yahoo.com

Received: 7 January 2021 Accepted: 13 February 2021 ePublished: 30 June 2021

\section{Introduction}

The progressive prevalence of coronavirus disease 2019 (COVID-19) has caused great stress and psychological strain (1). Pregnant women, healthcare providers, and patients with chronic conditions, respiratory disorders, and infectious diseases are more at risk for COVID-19 (2). Therefore, they more often resort to home quarantine, immunity boosting, and over-the-counter (OTC) use of medications in order to reduce the risk of affliction by COVID-19. However, these strategies may put them at risk for serious adverse events (3).

Healthcare providers, particularly nurses who provide care to patients with COVID-19, experience higher levels of fear and anxiety compared with the general public due to witnessing COVID-19-afflicted patients' suffering and having more information about COVID-19 and its prevalence. Therefore, they may resort to different strategies to reduce the risk of affliction by COVID-19 $(4,5)$ such as using contact precautions $(6)$ and reducing their workload (7). Because of their oversensitivity to COVID-19, nurses may immediately refer to physician and perform laboratory tests with experiencing mild symptoms of COVID-19 (8). Some of them may also start self-medication (SM) as soon as they experience COVID19-like symptoms which may be in fact due to problems such as fatigue, heavy workload, or psychological strains (9).

$\mathrm{SM}$ is a major healthcare challenge which is associated with many different problems such as increased medication use, high medication costs, medication resistance, medication dependence, drug interactions, encouragement of SM, and use of inappropriate medications or doses (10). Compared with the general public, SM is more prevalent among healthcare providers, particularly nurses. A meta-analysis reported that the prevalence of SM among nurses was five times greater than administrative hospital staff (11). A study into SM during the Middle East respiratory syndrome (MERS) in South Korea also found that SM among nurses who provided MERS care was three times greater than other nurses (12).

Despite the increasing prevalence of SM among nurses during the COVID-19 pandemic, there is limited reliable information about SM prevalence among nurses in Iran. Therefore, the present study sought to bridge this gap. The aim of the study was to evaluate SM, used medications, and symptoms among nurses providing care to pregnant

(C) 2021 The Author(s); Published by Shahrekord University of Medical Sciences. This is an open-access article distributed under the terms of the Creative Commons Attribution License (http://creativecommons.org/licenses/by/4.0), which permits unrestricted use, distribution, and reproduction in any medium, provided the original work is properly cited. 
women with COVID-19.

\section{Methods}

Design

This cross-sectional descriptive-analytical study was conducted in a four-month period from March 21 to July 22, 2020. Participants were 125 nurses conveniently selected from different wards of Imam Reza teaching hospital, Tabriz, Iran. Inclusion criteria were an associate degree or higher in nursing, a clinical work experience of at least one year, care provision to pregnant women with COVID-19, no affliction by COVID-19, no affliction by COVID-19 among family members, no treatment for COVID-19, no history of respiratory disorders, infectious diseases, and cardiovascular disease, and agreement for participation. Based on the results of a previous study (13) and with a confidence level of 0.95 , the minimum sample size was calculated to be 105 . Nonetheless, sample size was increased to 125 considering a probable attrition rate of $20 \%$.

\section{Instrument}

Data were collected using a sociodemographic characteristics questionnaire and a questionnaire on SM contributing factors. The sociodemographic characteristics questionnaire had items on age, educational level, work experience, and marital status. The questionnaire on SM contributing factors was developed by Tabiei et al. It has thirteen dichotomous Yes/No items on used medications (6 items) and symptoms (7 items). Tabiei et al confirmed the acceptable content validity and reliability of the questionnaire and reported that its Cronbach's alpha was 0.83 (14).

\section{Procedure}

Participants completed the study instruments through the self-report method. Their questions regarding the study instruments were answered and their ambiguities were clarified during data collection.

\section{Data analysis}

Questionnaires were initially assessed for any missing data and then, the data were entered into the SPSS software (v. 21.0) for analysis. Data were analyzed at a significance level of less than 0.05 using the chi-square test.

\section{Results}

Five participants were excluded due to incomplete answering to the study instruments and 120 participants with complete answers to their questionnaires were included in the final analysis. The mean of participants' age was $38.25 \pm 4.49$ years. Most participants were married (70\%), had bachelor's degree (65.33\%), and had a work experience of 5-15 years (54.17\%) (Table 1). None of the participants reported affliction by COVID-19.

The prevalence of SM was $40.83 \%$. The highest SM rate was among participants aged 20-30 years (27.50\%), married participants (25.83\%), participants with bachelor's degree (18.33\%), and participants with a work experience of 15-20 years (12.20\%). SM had significant relationship with educational level $(P=0.045)$ and work experience $(P=0.036)$ (Table 1$)$.

The most commonly used medications were antibiotics (63.26\%), herbal medicines (57.14\%), multivitamins (48.98\%), analgesics (42.85\%), and antihistamines (36.73\%). SM had significant relationship with the use of antibiotics $(P=0.012)$, herbal medicines $(P=0.028)$, multivitamins $(P=0.035)$, and analgesics $(P=0.044)$ (Table 2).

The most prevalent symptoms which had led to SM were nausea (71.42\%), fever (71.42\%), headache (67.34\%), myalgia (61.22\%), diarrhea (48.98\%), dyspnea (42.85\%), and allergy (40.81\%). SM had significant relationship with

Table 1. Participants' characteristics and their relationship with self-medication

\begin{tabular}{|c|c|c|c|c|c|}
\hline \multirow{2}{*}{ Characteristics } & & \multirow{2}{*}{ No. $(\%$} & \multicolumn{2}{|c|}{ Self-medication N (\%) } & \multirow{2}{*}{$P$ value $^{a}$} \\
\hline & & & Yes $(n=49)$ & No $(n=71)$ & \\
\hline \multirow{4}{*}{ Age (y) } & $20-30$ & $45(37.5)$ & 33 & 12 & \multirow{4}{*}{0.006} \\
\hline & $30-40$ & $32(26.66)$ & 3 & 29 & \\
\hline & $40-50$ & $30(25.00)$ & 8 & 22 & \\
\hline & $>50$ & $13(10.84)$ & 5 & 8 & \\
\hline \multirow{2}{*}{ Marital status } & Married & $84(70.00)$ & 31 & 53 & \multirow{2}{*}{0.019} \\
\hline & Single & $36(30.00)$ & 18 & 38 & \\
\hline \multirow{3}{*}{ Educational level } & Associate & $21(17.50)$ & 18 & 3 & \multirow{3}{*}{0.045} \\
\hline & Bachelor's & $79(65.33)$ & 22 & 57 & \\
\hline & Master's & $20(16.67)$ & 9 & 11 & \\
\hline \multirow{5}{*}{ Work experience (y) } & $<5$ & $19(15.83)$ & 9 & 10 & \multirow{5}{*}{0.036} \\
\hline & $5-10$ & $26(21.67)$ & 11 & 15 & \\
\hline & $10-15$ & $39(32.50)$ & 5 & 34 & \\
\hline & $15-20$ & $22(18.33)$ & 15 & 7 & \\
\hline & $>20$ & $14(11.67)$ & 9 & 5 & \\
\hline
\end{tabular}

${ }^{a}$ The results of the Chi-square test 
nausea $(P=0.036)$, fever $(P=0.019)$, headache $(P=0.044)$, and diarrhea $(P=0.021)$ (Table 3$)$.

\section{Discussion}

The aim of the study was to evaluate SM, used medications, and symptoms among nurses providing care to pregnant women with COVID-19. Findings showed that the prevalence of SM was around $41 \%$. This rate is higher than the rates reported in previous studies which were $23 \%$ (15) and 31\% (16). The higher prevalence of SM in the present study may be due to the high psychological strains associated with the COVID-19 as well as participants' fear over affliction by COVID-19 which might have moved nurses towards SM for prophylactic, therapeutic, and immunity boosting purposes.

Findings also revealed antibiotics, herbal medicines, multivitamins, analgesics, and antihistamines as the most commonly used medications by nurses. This is in line with the findings of several previous studies which reported that the most commonly used medications among nurses

Table 2. The relationship of self-medication with the used medications

\begin{tabular}{|c|c|c|c|}
\hline Medications & & $\begin{array}{c}\text { Self-medication N (\%) } \\
\text { Yes }(n=49)\end{array}$ & $P$ value* \\
\hline \multirow{2}{*}{ Antibiotics } & Yes & $31(63.26)$ & \multirow{2}{*}{0.012} \\
\hline & No & $18(36.63)$ & \\
\hline \multirow{2}{*}{$\begin{array}{l}\text { Herbal } \\
\text { medicines }\end{array}$} & Yes & $28(57.14)$ & \multirow{2}{*}{0.028} \\
\hline & No & $21(42.86)$ & \\
\hline \multirow{2}{*}{ Multivitamins } & Yes & 24 (48.98) & \multirow{2}{*}{0.035} \\
\hline & No & $25(49.02)$ & \\
\hline \multirow{2}{*}{ Analgesics } & Yes & $21(42.85)$ & \multirow{2}{*}{0.044} \\
\hline & No & $28(57.14)$ & \\
\hline \multirow{2}{*}{ Antihistamines } & Yes & $18(36.73)$ & \multirow{2}{*}{0.059} \\
\hline & No & 31 (63.26) & \\
\hline
\end{tabular}

a The results of the Chi-square test

Table 3. The relationship of self-medication with symptoms

\begin{tabular}{|c|c|c|c|}
\hline Medications & & $\begin{array}{c}\text { Self-medication N }(\%) \\
\text { Yes }(n=49)\end{array}$ & $P$ value $^{a}$ \\
\hline \multirow{2}{*}{ Dyspnea } & Yes & $21(42.85)$ & \multirow{2}{*}{0.219} \\
\hline & No & 28 (57.15) & \\
\hline \multirow{2}{*}{ Nausea } & Yes & 35 (71.24) & \multirow{2}{*}{0.036} \\
\hline & No & $14(28.86)$ & \\
\hline \multirow{2}{*}{ Fever } & Yes & 35 (71.24) & \multirow{2}{*}{0.19} \\
\hline & No & $14(28.86)$ & \\
\hline \multirow{2}{*}{ Headache } & Yes & $33(67.34)$ & \multirow{2}{*}{0.044} \\
\hline & No & $16(32.66)$ & \\
\hline \multirow{2}{*}{ Myalgia } & Yes & $30(61.22)$ & \multirow{2}{*}{0.193} \\
\hline & No & 19 (39.88) & \\
\hline \multirow{2}{*}{ Allergy } & Yes & $20(40.81)$ & \multirow{2}{*}{0.250} \\
\hline & No & 29 (49.19) & \\
\hline \multirow{2}{*}{ Diarrhea } & Yes & 44 (88.98) & \multirow{2}{*}{0.021} \\
\hline & No & $5(11.02)$ & \\
\hline
\end{tabular}

a The results of the Chi-square test.
What does this paper contribute to the wider global clinical community?

Study findings can be used to implement educational programs for nurses to inform them about the side effects of SM and OTC use of medications.

were analgesics (17), herbal medicines, multivitamins (18), antibiotics, and antihistamines $(17,19)$. The wide and easy availability of these medications is a major factor contributing to their OTC use by nurses, even in case of mild symptoms.

We also found that none of the participating nurses had been afflicted by COVID-19. The most common symptoms contributing to SM were dyspnea, nausea, fever, headache, diarrhea, allergy, and myalgia. This is in agreement with the findings of previous studies $(20,21)$. These symptoms are among the most common symptoms of COVID-19 and health problems such as food poisoning, heat exhaustion, fatigue, or heavy workload. The similarity of COVID-19 symptoms with the symptoms of conditions such as food poisoning, heat exhaustion, fatigue, or heavy workload may require nurses, who provide care to patients with COVID-19, to attribute these symptoms in themselves to COVID-19 and start SM.

Large sample size and high response rate were among the strengths of the present study. However, this study was conducted in a single setting and its findings may have limited generalizability. Future studies are recommended to implement educational programs for nurses on the side effects of SM as well as strategies for managing psychological strains during the COVID-19 pandemic.

\section{Conclusion}

This study shows the high prevalence of prophylactic and therapeutic SM among nurses who provide care to pregnant women with COVID-19, mostly due to chronic fatigue and fear over affliction by COVID-19.

\section{Acknowledgement}

We would like to thank all nurses who participated in this study.

\section{Conflict of Interests}

The authors declare no conflict of interests.

\section{Ethical Approval}

The Ethics Committee of Tabriz University of Medical Sciences, Tabriz, Iran, approved this study (code: IR.TBZMED. REC.1398.1306). Necessary arrangements for the study were made with the authorities of the study setting. Participants were provided with information about the study aim, voluntariness of participation, and exclusive use of their data for the present study. Written informed consent was obtained from all participants.

\section{References}

1. Zheng YY, Ma YT, Zhang JY, Xie X. COVID-19 and the cardiovascular system. Nat Rev Cardiol. 2020;17(5):259-60. doi: 10.1038/s41569-020-0360-5.

2. Haghdoost SM, Khanbabayi Gol M. The necessity of paying more attention to the neurological and psychological 
problems caused by COVID-19 pandemic during pregnancy. Int J Women's Health Reprod Sci. 2020;8(3):243-4. doi: 10.15296/ijwhr.2020.40.

3. Soroush A, Abdi A, Andayeshgar B, Vahdat A, Khatony A. Exploring the perceived factors that affect self-medication among nursing students: a qualitative study. BMC Nurs. 2018;17(1):35. doi: 10.1186/s12912-018-0302-2.

4. Mo Y, Deng L, Zhang L, Lang Q, Liao C, Wang N, et al. Work stress among Chinese nurses to support Wuhan in fighting against COVID-19 epidemic. J Nurs Manag. 2020;28(5):10029. doi: 10.1111/jonm.13014.

5. Sun N, Wei L, Shi S, Jiao D, Song R, Ma L, et al. A qualitative study on the psychological experience of caregivers of COVID-19 patients. Am J Infect Control. 2020;48(6):592-8. doi: 10.1016/j.ajic.2020.03.018.

6. Shanafelt T, Ripp J, Trockel M. Understanding and addressing sources of anxiety among health care professionals during the COVID-19 Pandemic. JAMA. 2020;323(21):2133-4. doi: 10.1001/jama.2020.5893.

7. Spoorthy MS, Pratapa SK, Mahant S. Mental health problems faced by healthcare workers due to the COVID-19 pandemic-a review. Asian J Psychiatr. 2020;51:102119. doi: 10.1016/j. ajp.2020.102119.

8. Huang L, Xu F, Liu H. Emotional responses and coping strategies of nurses and nursing college students during COVID-19 outbreak. medRxiv. 2020. doi: 10.1101/2020.03.05.20031898.

9. Gheysarzadeh A, Sadeghifard N, Safari M, Balavandi F, Falahi $S$, Kenarkoohi A, et al. Report of five nurses infected with severe acute respiratory syndrome coronavirus 2 during patient care: case series. New Microbes New Infect. 2020;36:100694. doi: 10.1016/j.nmni.2020.100694.

10. Kudyar P, Rani S, Malhotra P. Knowledge, attitude \& practice towards self-medication among nursing students in a teaching hospital of north India. India J Pharm Pharmacol. 2018;5(4):159-63. doi: 10.18231/2393-9087.2018.0033.

11. Torres NF, Chibi B, Middleton LE, Solomon VP, MashambaThompson TP. Evidence of factors influencing self-medication with antibiotics in low and middle-income countries: a systematic scoping review. Public Health. 2019;168:92-101. doi: 10.1016/j.puhe.2018.11.018.

12. Hwang JH, Cho HJ, Im HB, Jung YS, Choi SJ, Han D. Complementary and alternative medicine use among outpatients during the 2015 MERS outbreak in South Korea: a cross-sectional study. BMC Complement Med Ther. 2020;20(1):147. doi: 10.1186/s12906-020-02945-0.

13. Abdi A, Faraji A, Dehghan F, Khatony A. Prevalence of selfmedication practice among health sciences students in Kermanshah, Iran. BMC Pharmacol Toxicol. 2018;19(1):36. doi: 10.1186/s40360-018-0231-4.

14. Tabiei SH, Farajzadeh Z, Eizadpanah AM. Self-medication with drug amongst university students of Birjand. Mod Care J. 2012;9(4):371-77. [Persian].

15. Gama AS, Secoli SR. Self-medication among nursing students in the state of Amazonas - Brazil. Rev Gaucha Enferm. 2017;38(1):e65111. doi: 10.1590/1983-1447.2017.01.65111.

16. Williams A, Crawford K. Self-medication practices among undergraduate nursing and midwifery students in Australia: a cross-sectional study. Contemp Nurse. 2016;52(4):410-20. doi: 10.1080/10376178.2016.1197782.

17. Dutt HK, Sarkhil MZ, Abdul Hasseb M, Singh G. A comparative knowledge, attitude, and practice study of antimicrobial use, self-medication and antimicrobial resistance among final year students of MBBS, BDS, and BSc Nursing at a tertiary care hospital at Kannur. Natl J Physiol Pharm Pharmacol. 2018;8(9):1305-11. doi: 10.5455/ njppp.2018.8.0518130052018.

18. Sah AK, Jha RK, Shah DK. Self-medication with antibiotics among nursing students of Nepal. Int J Pharm Sci Res. 2016;7:427-30.

19. Parikh D, Sattigeri B, Kumar A, Brahmbhatt S. A Survey Study on Use of over the Counter (OTC) Drugs Among Medical Students, Nursing and Clerical Staff of a Tertiary Care Teaching Rural Hospital Authors Devang Parikh, Bm Sattigeri, Ashok Kumar, Shruthi Brahmbhatt (March 13, 2019). Available from: https://ssrn.com/abstract $=3352064$.

20. Sado E, Kassahun E, Bayisa G, Gebre M, Tadesse A, Mosisa B. Epidemiology of self-medication with modern medicines among health care professionals in Nekemte town, western Ethiopia. BMC Res Notes. 2017;10(1):533. doi: 10.1186/ s13104-017-2865-5.

21. Sajith M, Suresh SM, Roy NT, Pawar D. Self-medication practices among health care professional students in a tertiary care hospital, Pune. Open Public Health J. 2017;10(1):63-8. doi: 10.2174/1874944501710010063. 